\title{
Prevalence and Risk Factors for Lens Opacities in Nigeria: Results of the National Blindness and Low Vision Survey
}

\author{
Abdull M. Mahdi, ${ }^{1}$ Mansur Rabiu, ${ }^{2}$ Clare Gilbert,${ }^{3}$ Selvaraj Sivasubramaniam, ${ }^{3}$ \\ Gudlavalleti V. S. Murthy, ${ }^{4}$ Christian Ezelum, ${ }^{5}$ and Gabriel Entekume ${ }^{6}$; for the Nigeria National \\ Blindness and Visual Impairment Study Group
}

\author{
${ }^{1}$ Abubakar Tafawa Balewa University Teaching Hospital, Bauchi, Nigeria \\ ${ }^{2}$ Director Programs, Prevention of Blindness Union, Riyadh, Saudi Arabia \\ ${ }^{3}$ International Centre for Eye Health, London School of Hygiene \& Tropical Medicine, Keppel Street, London, United Kingdom \\ ${ }^{4}$ Indian Institute of Public Health, Public Health Foundation of India, Hyderabad, Andhra Pradesh, India \\ ${ }^{5}$ Ministry of Health, Awka, Anambra State, Nigeria \\ ${ }^{6}$ Vision Health Services, Ikeja, Lagos State, Nigeria
}

Correspondence: Gudlavalleti V. S. Murthy, Indian Institute of Public Health, Public Health Foundation of India, ANV Arcade, 1 Amar Coop Society, Kavuri Hills, Madhapur, Hyderabad, India 500033 ; gvsmurthy1956@gmail.com.

See the appendix for the members of the Nigeria National Blindness and Visual Impairment Study Group.

Submitted: May 31, 2012

Accepted: January 31, 2014

Citation: Mahdi AM, Rabiu M, Gilbert C, et al.; for the Nigeria National Blindness and Visual Impairment Study Group. Prevalence and risk factors for lens opacities in Nigeria: results of the National Blindness and Low Vision Survey. Invest Ophthalmol Vis Sci. 2014;55:2642-2651. DOI:10. $1167 /$ iovs.12-10303
Purpose. Investigate prevalence and risk factors for lens opacities among a nationally representative sample of Nigerians aged $\geq 40$ years.

Methods. Across 305 clusters, 13,591 adults were examined. Every seventh participant ( $n=$ 1722) was sampled systematically and examined in detail, including lens opacity grading. Lenses were examined at the slit-lamp with pupil dilation and graded using the World Health Organization (WHO) system. Significant opacities were defined as nuclear, cortical, or posterior subcapsular opacity of WHO grade $>1$, or hyper/mature cataract. The category "Any Opacity" included hyper/mature opacity and aphakia/pseudophakia/couching. Data were collected on sociodemographic and environmental factors, including height and weight.

REsults. A total of 1631/1722 (95\%) in the normative subsample had their lenses graded. Prevalence of "Any Opacity" was 19.8\% (95\% confidence interval [CI]: 7.9-21.7) the prevalence of all types increased with age, and was higher in females and those not literate. Prevalence of nuclear, cortical, and posterior subcapsular were 8.8\% (95\% CI: 7.5-10.1); 11.7\% (95\% CI: 10.0-13.3); and 2.9\% (95\% CI: 2.1-3.8), respectively. In multivariate analysis, age was an independent risk factor for all types. Nuclear opacity was also associated with female sex (odds ratio [OR] 2.4; 95\% CI: 1.5-3.6); lean body mass index (BMI; OR 2.0; 95\% CI: 1.1-3.5); and the Igbo ethnic group (OR 4.4; 95\% CI: 2.3-8.4). Cortical opacity was also associated with female sex (OR 2.1; 95\% CI: 1.5-3.0) and the Yoruba (OR 0.45; 95\% CI: 0.3$0.8)$, but not with BMI. "Other Lens Opacities," which includes couching, was significantly lower in the Guinea savannah region (OR $0.4 ; 95 \% \mathrm{CI}: 0.2-0.9$ ), while living in rain forest areas was protective for posterior subcapsular cataracts (OR 0.3 ; 95\% CI: 0.1-0.7).

Conclusions. A fifth of Nigerian adults have some degree of lens opacity. Further studies are needed to investigate the role of ethnicity, climate variables, and other risk factors.

Keywords: cataract risk factors, lens opacities, epidemiology, Nigeria, prevalence
$\mathbf{R}^{\mathrm{i}}$ isk factors for cataract have been extensively researched and reviewed, ${ }^{1}$ with studies being undertaken in many countries in different regions. There have also been twin and family studies, which indicate that some forms of lens opacity have a genetic component. ${ }^{2,3}$ The majority of studies show that increasing age, female sex, exposure to free radicals from smoking 4,5 and diabetes, and steroid medication increase the risk. ${ }^{1}$ While a diet low in antioxidants is associated with an increased risk in some studies, supplementation trials have been largely negative. ${ }^{5}$ However, most studies have been undertaken in affluent societies where diets are good and exposure to solar radiation is limited, which is very different from developing countries where cataract is not only more prevalent but also occurs at a younger age. ${ }^{6,7}$ Additional risk factors of relevance to developing countries are ultraviolet light exposure,${ }^{8,9}$ exposure to biomass fuels, ${ }^{10,11}$ body mass index
(BMI), ${ }^{12}$ episodes of severe dehydration, ${ }^{13}$ and childbearing in women. ${ }^{14}$

Data from a recent large, population-based survey in Pakistan showed that high ambient temperature and household deprivation were also associated with lens opacities (LO) in addition to age and sex, with body mass index showing a "J" shaped association. ${ }^{7}$ However, evidence from other developing countries is scarce. This paper presents data on the prevalence and risk factors for LO, which were collected during the Nigeria national survey of visual impairment and blindness.

Nigeria is the most populous country in Africa, which had a total population of 135 million at the time of the survey, $16.9 \%$ of whom were aged 40 years and older. Nigeria has more than 250 different ethnic groups, the largest being the Hausa, Yoruba, Ibo, and Fulani with varying languages, diets, customs, and livelihoods. There are six large administrative divisions, 


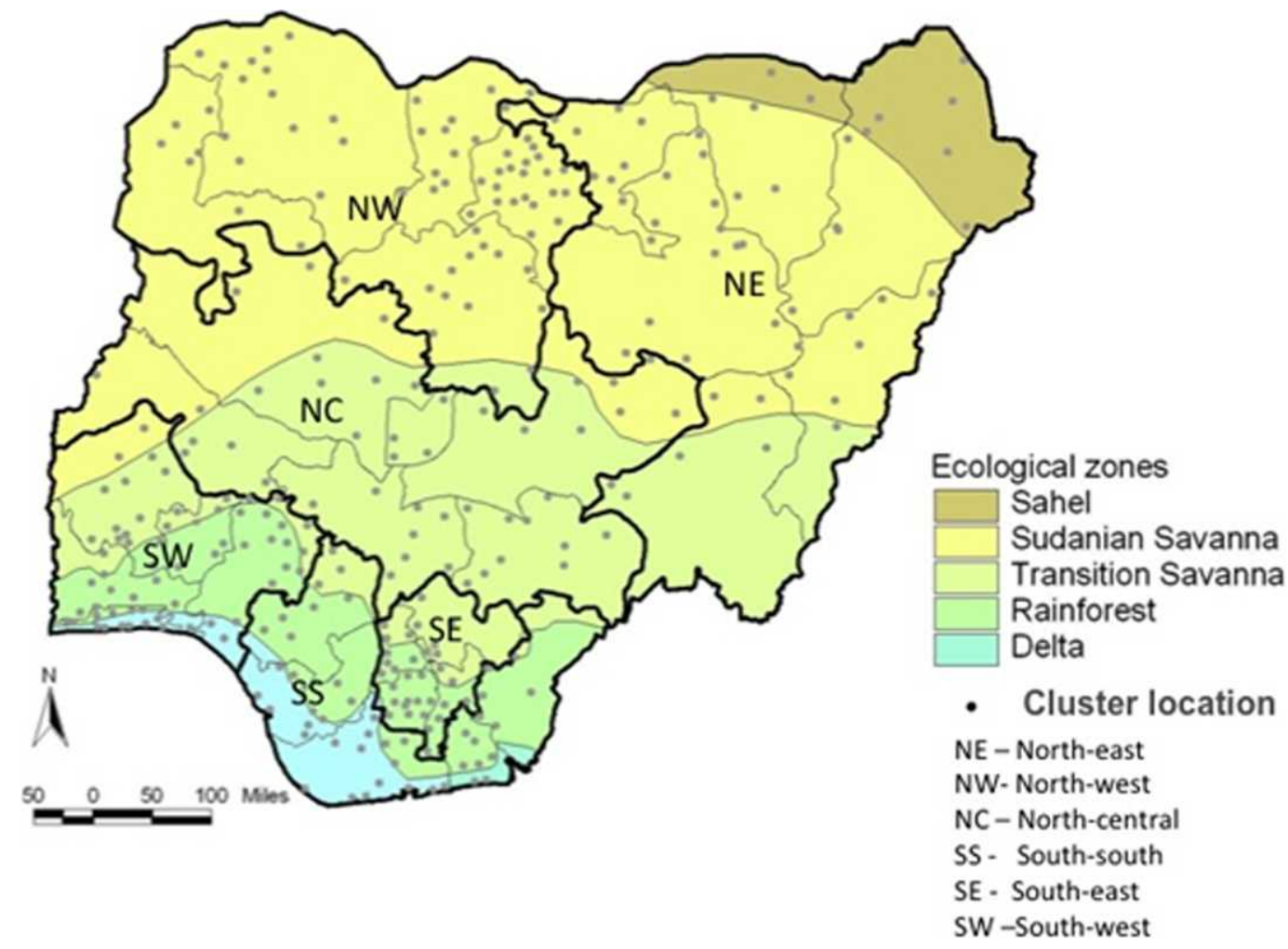

Figure 1. Map of Nigeria showing distribution of clusters.

called geopolitical zones, namely northwest, north central, northeast, southwest, south-south and southeast. Each geopolitical zone is subdivided in states. Nigeria has a tropical climate with high year-round annual temperatures, but the north has lower annual rainfall and more annual hours of sunshine. The country is divided into several different ecological zonesdelta (south), rainforest (south and central), savannah (central and north), and Sahel (far northeast).

\section{MeTHODS}

A detailed description of the methods used in the survey has already been published. ${ }^{15}$ A brief summary of the methods pertinent to this paper is described.

\section{Sample Size}

The sample size for the main survey $(15,027)$ was calculated based on an assumed prevalence of blindness (presenting visual acuity [VA] of less than $3 / 60$ in the better eye) of $5 \%$ among those aged 40 years and older, a precision of $0.5 \%$, a $95 \%$ confidence interval (CI), a design effect of 1.75 , and a response rate of $85 \%$. The "normative sample" included in this study was identified by systematically recruiting every seventh participant who attended the examination site. This yielded a sample of 1722 individuals aged 40 years and older.

\section{Sampling Strategy}

Multistage stratified cluster random sampling, with probability proportional to size procedures, was used to identify 310 clusters across all geopolitical zones. The cluster distribution was north central $(n=45)$, northeast $(n=41)$, northwest ( $n=$ $80)$, southeast $(n=36)$, south-south $(n=45)$, and southwest geopolitical zone ( $n=63$; Fig. 1$)$. However, because of civil disturbances, three clusters in south-south and two clusters in southeast were excluded. Enumerated individuals were asked to attend the survey clinical station that was set up in the local community. Individuals unable to attend were examined in their homes. Two teams worked concurrently in different clusters and each team had two experienced ophthalmologists who undertook the lens grading.

\section{Clinical Examination}

All participants in the normative sample were interviewed to assess ethnic group, history of diabetes mellitus, and history of cataract surgery or couching. At the examination site, all underwent distance VA measurement (i.e., with usual correction) with a reduced logMAR E-chart in each eye. All participants had their height and weight measurement by a nurse using standard equipment. All participants in the normative sample underwent detailed examination by one of two fully qualified ophthalmologists who had been trained in all the survey methods, including lens grading. Data were collected over a 30-month period from January 2005 to July 2007.

\section{Examination of the Lens}

The World Health Organization (WHO) system classifies the type and severity of different types of opacity. ${ }^{16}$ The method entails slit lamp examination of the lens after dilating the pupil. The degree of lens opacity is assessed in each eye by comparison against standard photographs for nuclear opacities. In grading cortical opacity, the proportion of lens circumference affected is assessed, and posterior subcapsular cataracts are graded according to the size of opacity in millimeters. Anyone with an anterior chamber depth $\leq 1 / 4$ the corneal thickness (Van Herrick Angle grade 2 or less) was excluded. 


\section{Quality Assurance}

The core team of ophthalmologists and optometrists underwent 4-week training at the beginning of the survey, with additional training sessions at the beginning of fieldwork in each geopolitical zone. Interobserver assessments were undertaken for VA measurement but not for lens opacity grading. Other quality assurance procedures included a random verification of data entered on the data recording forms in the field and at the project office, use of a survey manual of operations, regular monitoring by the project manager, and an advisory committee that monitored progress.

\section{Statistical Analysis}

Significant lens opacity was defined as either nuclear (NO), cortical (CO), or posterior subcapsular lens opacity (PSC) WHO grades $>1$, or hyper/mature cataract. A category labeled "Other" was created for eyes that had undergone cataract surgery or couching. Individuals included in the normative database were used in this analysis as they all underwent lens grading. Individuals with central corneal opacity or trauma that precluded lens grading were excluded. If the grades differed between eyes, the eye with the highest grade was selected for analysis. Individuals with significant mixed lens opacities in the eye used for analysis were included in risk factor analyses for both types of opacity.

Body mass index was categorized as lean: $<18.5$; normal: $\geq 18.5$ to $<25.0$; overweight: $\geq 25.0$ to $<30.0$; and obese: $\geq 30$.0. Literacy was determined at the individual level and at the household level and both had two categories: illiterate/ reads or writes with difficulty and literate. The household literacy variable used the highest level of literacy of household members. An environment and sanitation index was created using a combination of data on water supply and sanitation at the household level: very good (tap water and flush latrine); good (bore well or unprotected water supply and flush latrine); poor (tap water and pit or bush latrine); or very poor (bore well or unprotected water supply and pit or bush latrine). Ethnic group data was self-reported, and ethnic groups represented by more than 40 participants were analyzed separately. Data were not collected on cigarette smoking as this is very uncommon in Nigeria.

A customized database was created using a database management system (Microsoft Access; Microsoft Corp., Redmond, WA, USA) and data were double entered. All data were then transferred to the International Centre for Eye Health, where data cleaning and analysis were performed using a commercial statistical package (Stata 11.0; StataCorp, College Station, TX, USA).

Data are presented on the prevalence of lens opacity for different socio-demographic groups. Risk factors for lens opacity are described in relation to specific socio-demographic characteristics, such as literacy and BMI. Design based Fstatistics were calculated to establish associations between the prevalence of lens opacity and the risk factors. Univariate and age-sex adjusted logistic regression modeling were used to explore associations with demographic factors. Variables which were significant at the 0.2 level in univariate analyses were included in the multivariable model. Pairwise interactions were assessed simultaneously using a Wald $F$ test. Multiple regression estimates of the independent effects of model variables were considered reliable only when interactions between these variables were not significant. Missing values were assumed to be distributed the same as available data, and thus were excluded in all analyses.

The design effect due to stratified cluster sampling was taken into account in univariate and multivariate analyses to calculate confidence intervals for prevalence estimates and odds ratios in the regression modeling. We used "svy" commands in the
Table 1. Characteristics of All Survey Participants and Those in the Normative Sample

\begin{tabular}{|c|c|c|c|c|c|}
\hline & \multicolumn{2}{|c|}{$\begin{array}{l}\text { Survey } \\
\text { Sample }\end{array}$} & \multicolumn{2}{|c|}{$\begin{array}{c}\text { Normative } \\
\text { Sample }\end{array}$} & \multirow[b]{2}{*}{$P$ Value } \\
\hline & $n$ & $\%$ & $n$ & $\%$ & \\
\hline \multicolumn{6}{|l|}{ Age group, y } \\
\hline $40-49$ & 4,889 & 36.0 & 581 & 35.5 & 0.34 \\
\hline $50-59$ & 3,577 & 26.3 & 427 & 26.1 & \\
\hline $60-69$ & 2,773 & 20.4 & 345 & 21.1 & \\
\hline $70-79$ & 1,653 & 12.2 & 213 & 13.0 & \\
\hline $80+$ & 699 & 5.1 & 71 & 4.3 & \\
\hline \multicolumn{6}{|l|}{ Sex } \\
\hline Male & 6,246 & 46.0 & 765 & 46.7 & 0.47 \\
\hline Female & 7,345 & 54.0 & 872 & 53.3 & \\
\hline \multicolumn{6}{|l|}{ Geopolitical zone } \\
\hline Northeast & 1,727 & 12.7 & 201 & 12.3 & 0.02 \\
\hline Southeast & 1,662 & 12.2 & 198 & 12.1 & \\
\hline South-south & 1,852 & 13.6 & 232 & 14.2 & \\
\hline Northwest & 3,593 & 26.4 & 434 & 26.5 & \\
\hline Southwest & 2,728 & 20.1 & 308 & 18.8 & \\
\hline North central & 2,029 & 14.9 & 264 & 16.1 & \\
\hline \multicolumn{6}{|l|}{ BMI } \\
\hline Lean & 1,502 & 11.1 & 195 & 12.1 & 0.62 \\
\hline Normal & 8,182 & 60.2 & 986 & 61.0 & \\
\hline Heavy & 2,597 & 19.1 & 303 & 18.8 & \\
\hline Obese & 1,118 & 8.2 & 132 & 8.2 & \\
\hline Missing & 192 & 1.4 & 21 & 1.3 & \\
\hline \multicolumn{6}{|l|}{ Literacy } \\
\hline Literate & 5,925 & 43.6 & 727 & 44.4 & 0.40 \\
\hline Illiterate & 7,666 & 56.4 & 910 & 55.6 & \\
\hline \multicolumn{6}{|l|}{ Residence } \\
\hline Urban & 3,051 & 22.5 & 371 & 22.7 & 0.63 \\
\hline Rural & 10,540 & 77.6 & 1,266 & 77.3 & \\
\hline \multicolumn{6}{|c|}{ Household literacy } \\
\hline Literate & 7,872 & 57.9 & 952 & 58.2 & 0.81 \\
\hline Illiterate & 5,719 & 42.1 & 685 & 41.8 & \\
\hline \multicolumn{6}{|c|}{ Environmental and sanitation index* } \\
\hline Very good & 760 & 5.6 & 102 & 6.2 & 0.16 \\
\hline Good & 656 & 4.8 & 70 & 4.3 & \\
\hline Poor & 3,138 & 23.1 & 374 & 22.9 & \\
\hline Very poor & 9,031 & 66.5 & 1,091 & 66.7 & \\
\hline Missing & 6 & 0.0 & 0 & 0.0 & \\
\hline \multicolumn{6}{|l|}{ Ethnic group } \\
\hline Hausa & 3,377 & 24.9 & 402 & 24.6 & 0.41 \\
\hline Yoruba & 2,547 & 18.7 & 291 & 17.8 & \\
\hline Igbo & 2,023 & 14.9 & 245 & 15.0 & \\
\hline Fulani & 840 & 6.2 & 104 & 6.4 & \\
\hline Tiv & 342 & 2.5 & 43 & 2.6 & \\
\hline Others & 4,404 & 32.4 & 544 & 33.2 & \\
\hline Missing & 58 & 0.4 & 8 & 0.5 & \\
\hline \multicolumn{6}{|l|}{ Ecological zone } \\
\hline Sahel/ss & 5,584 & 41.1 & 671 & 41.0 & 0.33 \\
\hline GFSav & 3,453 & 25.4 & 423 & 25.8 & \\
\hline Rainforest & 3,220 & 23.7 & 376 & 23.0 & \\
\hline Delta & 1,334 & 9.8 & 167 & 10.2 & \\
\hline Total & 13,591 & 100.0 & 1,637 & 100.0 & \\
\hline
\end{tabular}

GFSav, Guinea Forest; SS, Sudanese Savannah.

* Household level indicator: very good (tap water and flush latrine); good (bore well or unprotected water supply and flush latrine); poor (tap water and pit or bush latrine); very poor (bore well or unprotected water supply and pit or bush latrine). 


\begin{tabular}{|c|c|}
\hline $\begin{array}{c}15,122 \\
\text { Enumerated }\end{array}$ & 1,531 \\
Nan-respandents \\
\hline
\end{tabular}

\begin{tabular}{|c|}
\hline 13,591 \\
Examined \\
\hline
\end{tabular}

\begin{tabular}{|c|c|}
\hline 1,722 & 85 \\
Nomative sample:1 in 8 & Refused examination \\
&
\end{tabular}

1,637

nHo lens grading
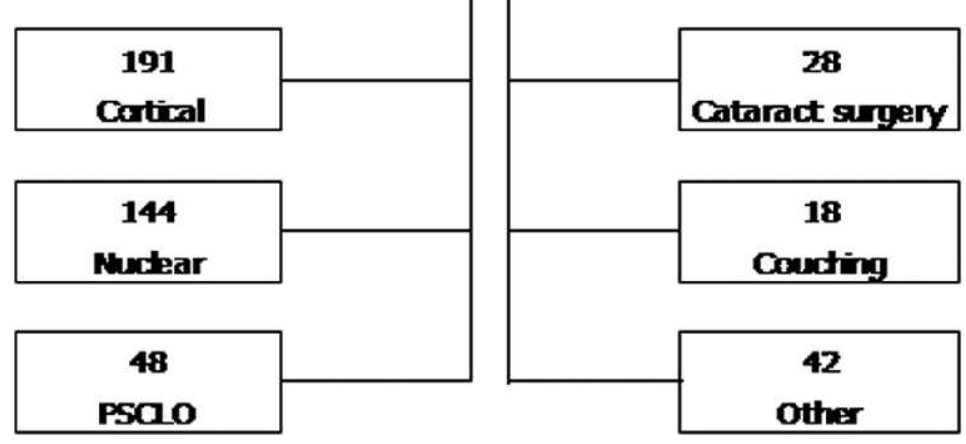

Figure 2. Flow chart of examination and lens grading.

statistical software program (StataCorp), which use linearized variance estimators based on first-order Taylor series linear approximation to compute the standard errors to account for clustering effects due to the sampling strategy.

\section{Ethical Approval}

The London School of Hygiene \& Tropical Medicine and the federal government of Nigeria provided ethical approval. The

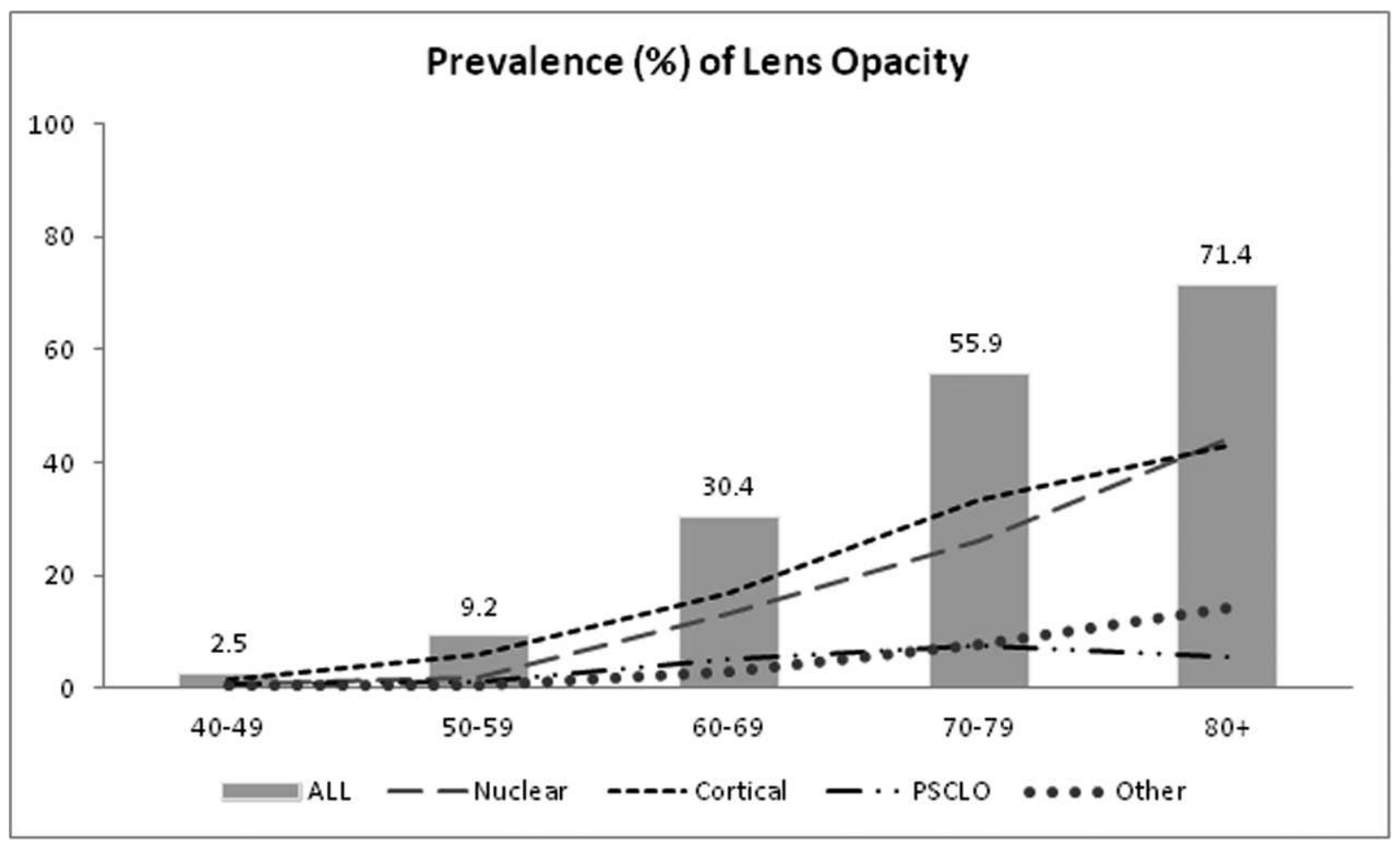

Figure 3. Prevalence of lens opacity by lens type and age group ALL, nuclear, cortical, posterior subcapsular lens opacity (PSCLO), and other combined. Other, hypermature cataract, couched, and operated eyes. 
TABLE 2. Demographic Distribution and Prevalence of Morphological Types of Lens Opacity

\begin{tabular}{|c|c|c|c|c|c|c|c|c|c|c|c|c|c|c|c|c|}
\hline & \multirow[b]{2}{*}{$n$} & \multicolumn{3}{|c|}{ Any Opacity* } & \multicolumn{3}{|c|}{ Cortical Opacity } & \multicolumn{3}{|c|}{ Nuclear Opacity } & \multicolumn{3}{|c|}{ PSC Opacity } & \multicolumn{3}{|c|}{ Other Opacity $\dagger$} \\
\hline & & $n$ & Prev & $95 \% \mathrm{CI}$ & $n$ & Prev & $95 \% \mathrm{CI}$ & $n$ & Prev & $95 \% \mathrm{CI}$ & $n$ & Prev & $95 \% \mathrm{CI}$ & $n$ & Prev & $95 \% \mathrm{CI}$ \\
\hline \multicolumn{17}{|c|}{ Age group, y } \\
\hline $40-49$ & 581 & 15 & 2.6 & $1.3,3.9$ & 9 & 1.5 & $0.5,2.6$ & 5 & 0.9 & $0.1,1.6$ & 5 & 0.9 & $0.1,1.6$ & 3 & 0.5 & $0.0,1.1$ \\
\hline $50-59$ & 427 & 39 & 9.1 & $6.3,12.0$ & 26 & 6.1 & $3.7,8.5$ & 9 & 2.1 & $0.7,3.5$ & 5 & 1.2 & $0.1,2.2$ & 3 & 0.7 & $0.0,1.5$ \\
\hline $60-69$ & 345 & 102 & 29.6 & $24.8,34.3$ & 56 & 16.2 & $12.4,20$ & 45 & 13 & $9.6,16.5$ & 17 & 4.9 & $2.7,7.2$ & 10 & 2.9 & $1.2,4.6$ \\
\hline $70-79$ & 213 & 117 & 54.9 & $48.4,61.4$ & 70 & 32.9 & $26.2,39.6$ & 54 & 25.4 & $19.5,31.2$ & 16 & 7.5 & $3.8,11.2$ & 16 & 7.5 & $4.0,11.0$ \\
\hline $80+$ & 71 & 51 & 71.8 & $61.3,82.3$ & 30 & 42.3 & $30.8,53.7$ & 31 & 43.7 & $32.2,55.1$ & 5 & 7.0 & $1.0,13.1$ & 10 & 14.1 & $6.3,21.9$ \\
\hline \multicolumn{17}{|l|}{ Sex } \\
\hline Male & 765 & 126 & 16.5 & $13.8,19.2$ & 72 & 9.4 & $7.2,11.6$ & 54 & 7.1 & $5.2,8.9$ & 21 & 2.7 & $1.6,3.9$ & 21 & 2.7 & $1.6,3.9$ \\
\hline Female & 872 & 198 & 22.7 & $20.0,25.4$ & 119 & 13.6 & $11.4,15.9$ & 90 & 10.3 & $8.3,12.3$ & 27 & 3.1 & $1.9,4.3$ & 21 & 2.4 & $1.4,3.4$ \\
\hline \multicolumn{17}{|c|}{ Geopolitical zone } \\
\hline $\mathrm{NE}$ & 201 & 53 & 26.4 & $20.0,32.7$ & 31 & 15.4 & $10.4,20.5$ & 27 & 13.4 & $9.1,17.8$ & 9 & 4.5 & $1.6,7.4$ & 8 & 4.0 & $1.4,6.5$ \\
\hline SE & 198 & 59 & 29.8 & $24.6,35.0$ & 28 & 14.1 & $9.1,19.2$ & 39 & 19.7 & $14.7,24.7$ & 4 & 2.0 & $0.1,3.9$ & 4 & 2.0 & $0.1,3.9$ \\
\hline SS & 232 & 50 & 21.6 & $15.5,27.6$ & 32 & 13.8 & $8.3,19.3$ & 25 & 10.8 & $6.8,14.7$ & 4 & 1.7 & $0.1,3.3$ & 3 & 1.3 & $0.0,2.7$ \\
\hline NW & 434 & 72 & 16.6 & $12.9,20.3$ & 45 & 10.4 & $7.4,13.3$ & 24 & 5.5 & $3.4,7.7$ & 16 & 3.7 & $1.8,5.6$ & 15 & 3.5 & $1.8,5.2$ \\
\hline SW & 308 & 54 & 17.5 & $13.7,21.3$ & 35 & 11.4 & $8.1,14.7$ & 18 & 5.8 & $3.3,8.4$ & 8 & 2.6 & $0.7,4.5$ & 7 & 2.3 & $0.7,3.9$ \\
\hline $\mathrm{NC}$ & 264 & 36 & 13.6 & $9.5,17.8$ & 20 & 7.6 & $4.4,10.8$ & 11 & 4.2 & $2.0,6.3$ & 7 & 2.7 & $0.5,4.8$ & 5 & 1.9 & $0.3,3.5$ \\
\hline \multicolumn{17}{|c|}{ Ethnic group } \\
\hline Hausa & 402 & 68 & 16.9 & $13.1,20.7$ & 47 & 11.7 & $8.5,14.9$ & 24 & 6.0 & $3.6,8.3$ & 15 & 3.7 & $1.8,5.7$ & 12 & 3.0 & $1.4,4.5$ \\
\hline Yoruba & 291 & 50 & 17.2 & $13.2,21.1$ & 27 & 9.3 & $5.9,12.7$ & 19 & 6.5 & $3.8,9.3$ & 8 & 2.7 & $0.7,4.8$ & 7 & 2.4 & $0.7,4.1$ \\
\hline Igbo & 245 & 67 & 27.3 & $22.5,32.2$ & 32 & 13.1 & $8.7,17.5$ & 43 & 17.6 & $13.2,21.9$ & 6 & 2.4 & $0.6,4.3$ & 4 & 1.6 & $0.1,3.2$ \\
\hline Fulani & 104 & 27 & 26.0 & $17.5,34.4$ & 12 & 11.5 & $5.6,17.5$ & 12 & 11.5 & $5.1,18.0$ & 5 & 4.8 & $0.9,8.7$ & 6 & 5.8 & $1.6,10.0$ \\
\hline Tiv & 43 & 8 & 18.6 & $9.1,28.1$ & 5 & 11.6 & $2.2,21.0$ & 2 & 4.7 & $0.0,10.1$ & 0 & 0 & 0 & 1 & 2.3 & $0.0,6.7$ \\
\hline Others & 544 & 103 & 18.9 & $15.2,22.7$ & 67 & 12.3 & $9.2,15.4$ & 44 & 8.1 & $5.8,11.8$ & 14 & 2.6 & $1.1,4.0$ & 12 & 2.2 & $1.0,3.4$ \\
\hline Missing & 8 & & & & & & & & & & & & & & & \\
\hline
\end{tabular}

NE, northeast; SE, southeast; SS, south-south; NW, northwest; SW, southwest; NC, north central.

* Any opacity: nuclear, cortical, PSC, and other combined.

† Other opacity: hypermature cataract, couched and operated eyes.

study adhered to the tenets of the Declaration of Helsinki. Written informed consent was obtained from all participants before they were examined. Eye examination and simple treatment (e.g., topical antibiotics and glasses) were provided to all individuals, regardless of their consent to participate in the study. Those needing further assessment and treatment (including cataract surgery) were referred to appropriate centers.

\section{RESULTS}

A total of 13,591 participants were examined, 1722 (12.7\%) of whom were included in the normative sample. There were no significant differences between the study population overall and the normative group in terms of age, sex, literacy, residence, environmental sanitation index, and household literacy (Table 1). In one geopolitical zone, the normative sample was slightly larger than expected (by 33 individuals) and slightly lower (by 10 individuals) in another. A total of 1637 participants (95\%) had a full examination with WHO lens grading (Fig. 2). Twenty-eight (1.7\%) had undergone cataract surgery and $1.1 \%(n=18)$ had been couched.

The prevalence of all types of lens opacity and any opacity by age are shown in Figure 3.

Nuclear Opacities. The prevalence of NO was 8.8\% (95\% CI 7.5\%-10.1\%; Table 2), being higher in females than males (10.3\% vs. $7.4 \%)$ and those who were illiterate compared with those who were literate ( $12.4 \%$ vs. $4.3 \%$; Tables 2,3$)$. There was also geographical variation, with the southeast geopolitical zone having the highest prevalence of literacy (19.7\%) and north central the lowest $(4.2 \%)$. On multivariate analysis, the risk of NO increased with each 10-year increase in age odds ratio [OR] 3.18; $95 \% \mathrm{CI}: 2.67 \%-3.79 \%$ ), and was significantly higher in females (OR 2.14; 95\% CI: $1.50 \%-3.04 \% ; P=0.001$ ); the Igbo ethnic group (OR 4.41; 95\% CI: $2.31 \%-8.40 \% ; P=$ $0.001)$; and those with a lean BMI (OR 2.01; 95\% CI: $1.15 \%-$ $3.52 \% ; P=0.014$; Table 4).

Cortical Opacities. Prevalence of CO was $11.7 \%$ (95\% CI: $10.0 \%-13.3 \%)$, being higher in females than males (13.6\% vs. 9.4\%) and among those who were illiterate compared with literates ( $15.6 \%$ vs. $6.7 \%$; Tables 2 , 3). On multivariate analysis, the risk of CO increased with each 10-year increase in age (OR 2.74; $95 \%$ CI: $2.37 \%-3.15 \% ; P=0.001)$ and was significantly higher in females than males (OR 2.14; 95\% CI: 1.50\%-3.04\%; $P$ $=0.001$ ). The Yoruba ethnic group had a significantly lower prevalence than other ethnic groups (OR: 0.45 ; 95\% CI: $0.25 \%-$ $0.8 \% ; P=0.007$; Table 4).

Posterior Subcapsular Lens Opacities. Posterior subcapsular lens opacities had the lowest prevalence, at 2.9\% (95\% CI: $2.1 \%-3.8 \%$ ) being higher in females than males (3.1\% vs. $2.7 \%$ ) and increased with age. In multivariate analyses, increasing age was associated with PSC (OR: 1.89 ; 95\% CI: $1.55 \%-2.29 \% ; P=$ 0.001), while living in the rainforest ecological zone was protective (OR: 0.36 ; 95\% CI: $0.15 \%-0.89 \% ; P=0.028$ ).

Any Lens Opacity. The prevalence of any lens opacity was 19.8\% (95\% CI: $17.9 \%-21.7 \%)$, which increased with age: from $2.6 \%$ (95\% CI: $1.3 \%-3.9 \%$ ) in those aged 40 to 49 years to $71.8 \%$ (95\% CI: $61.3 \%-82.3 \%$ ) in those aged 80 years and older. In univariate analyses, the prevalence of any lens opacity was higher in females than males (22.7\% vs. $16.5 \%)$; among those who were illiterate compared with those who were literate ( $26.7 \%$ vs. $11.1 \%$ ); those living in the southeast or northeast geopolitical zone (29.8\% and 26.4\%); the Igbo (27.3\%; 95\% CI: 
TABLE 3. Risk Factors for Lens Opacities

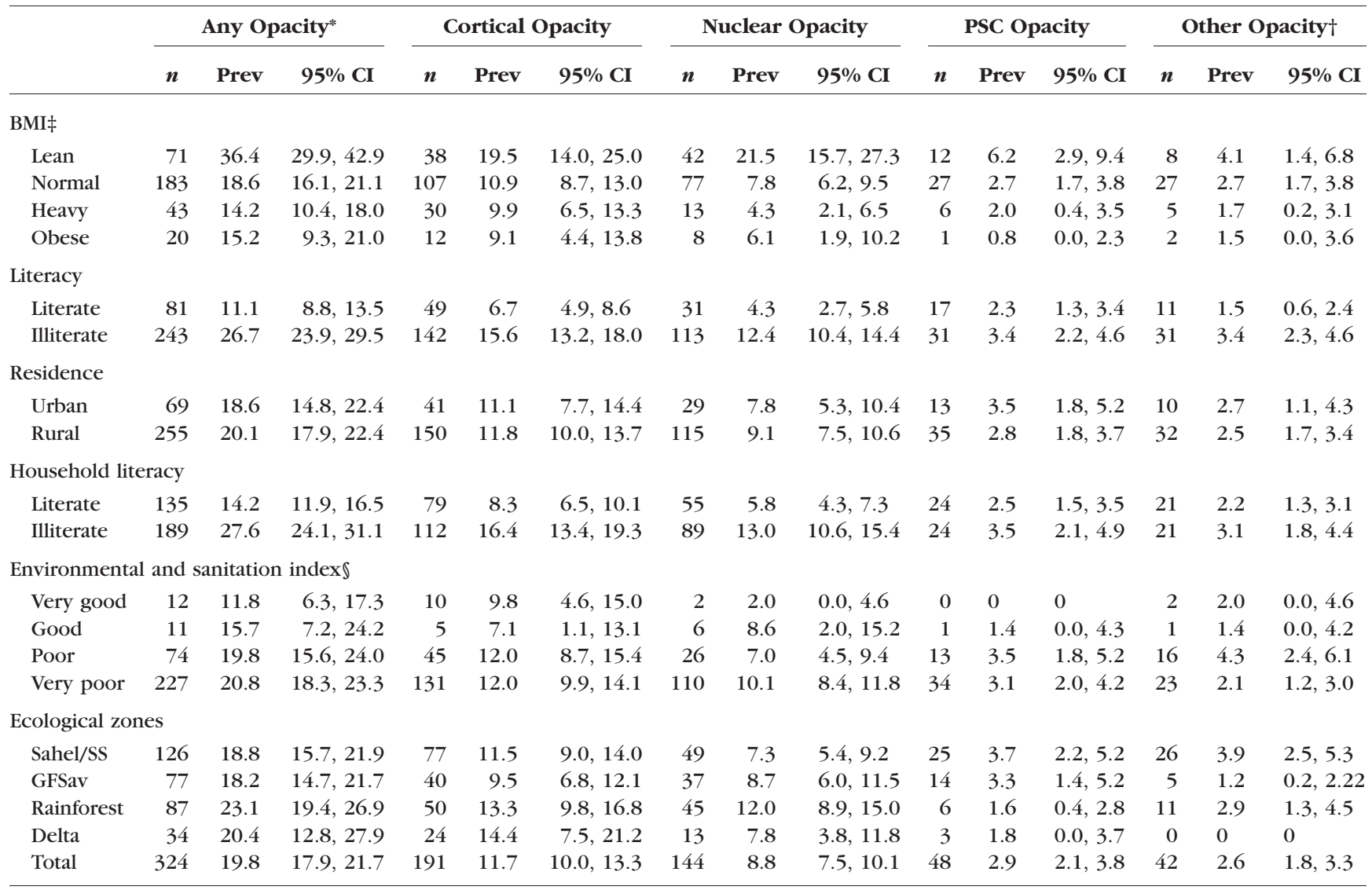

Env, environment; SS, Sudanese Savannah.

* Any opacity: nuclear, cortical, PSC, and other combined.

† Other opacity: hypermature cataract, couched, and operated eyes.

‡ Persons with missing BMI data $(n=21)$ were excluded.

$\S$ Household level indicator: very good (tap water and flush latrine); good (bore well or unprotected water supply and flush latrine); poor (tap water and pit or bush latrine); very poor (bore well or unprotected water supply and pit or bush latrine).

22.5\%-32.2\%) and Fulani (26\%; 95\% CI: 17.5\%-34.4\%) ethnic groups; and those living in an illiterate household (27.6\%; $95 \%$ CI: $24.1 \%-31.1 \%)$. On multivariate analysis, the risk of any lens opacity increased significantly with each 10-year increase in age (OR 3.66; 95\% CI: 3.17\%-4.23\%; $P=0.001$ ) and was greater in females (OR 2.47; 95\% CI: $1.81 \%-3.34 \% ; P=0.001)$ and the Igbo ethnic group (OR 1.93; 95\% CI: 1.24-3.01; $P=0.004$; Table 4). The Yoruba ethnic group had significantly less lens opacities (OR: 0.54; 95\% CI: $0.34 \%-0.88 \% ; P=0.014$ ).

Scoring of Lens Opacities by Ophthalmologist. Two qualified ophthalmologists undertook $80 \%$ of all lens grading. Their scores for grading lenses were $76.5 \%$ and $69.0 \%$ for no nuclear opacity; $72.2 \%$ and $75.2 \%$ for no cortical opacity; and $93.7 \%$ and $90.7 \%$ for no PSC.

\section{Discussion}

Most studies of risk factors for the different morphological types of lens opacity have used the Lens Opacities Classification System (LOCS). However, the WHO grading system was used in this survey for its ease of use in the field. ${ }^{16}$ As with LOCS and other grading systems, WHO grading requires dilation of the pupils, allowing peripheral opacities to be identified and graded. The WHO grading system is similar to the LOCS II system (with grading 0-3 for different morphological types of lens opacities), but differs from the LOCS III system, which has more steps and grades. Hence, the results from this paper can be compared with papers using the LOCS II system for those with grades 0 to 3 , but not grades 7 to $9 .^{17}$

In this survey, $\mathrm{CO}$ was the most frequent type, followed by $\mathrm{NO}$, and then PSC, a finding reported in another study in western Nigeria (Table 5), ${ }^{18}$ Tanzania, ${ }^{19}$ and surveys in Barbados $^{20}$ and in the United States of people of African descent, ${ }^{21}$ and Sri Lanka. ${ }^{22}$ This contrasts with surveys in India,,${ }^{6,23,24}$ Australia, ${ }^{25}$ Taiwan, ${ }^{26}$ Finland, ${ }^{27}$ China, ${ }^{28}$ and Myanmar where NO predominated. ${ }^{29}$ More population-based data on the morphological types of opacities are required from Africa to explore reasons for the differences between regions. One explanation for the predominance of $\mathrm{CO}$ in our study is that Nigeria lies near the equator, with high sunlight intensity particularly in northern areas, as ultraviolet light is an important risk factor for $\mathrm{CO}^{8}$ Another reason may be because cigarette smoking, a risk factor for $\mathrm{NO}$, is uncommon in Africa, including Nigeria. A limitation of our study is that exposure to cigarette smoking was not assessed.

Age is a consistent risk factor for cataract in all studies, ${ }^{1}$ and was also observed in Nigeria. Lens opacity was more common in females than males for all morphological types and for any lens opacity, which includes those who had had undergone a procedure for cataract. This sex difference has been reported in many other studies, ${ }^{30,31}$ but underlying biological mechanisms have not been fully elucidated. In India, a study of presenile cataract in women suggested that childbearing may be 


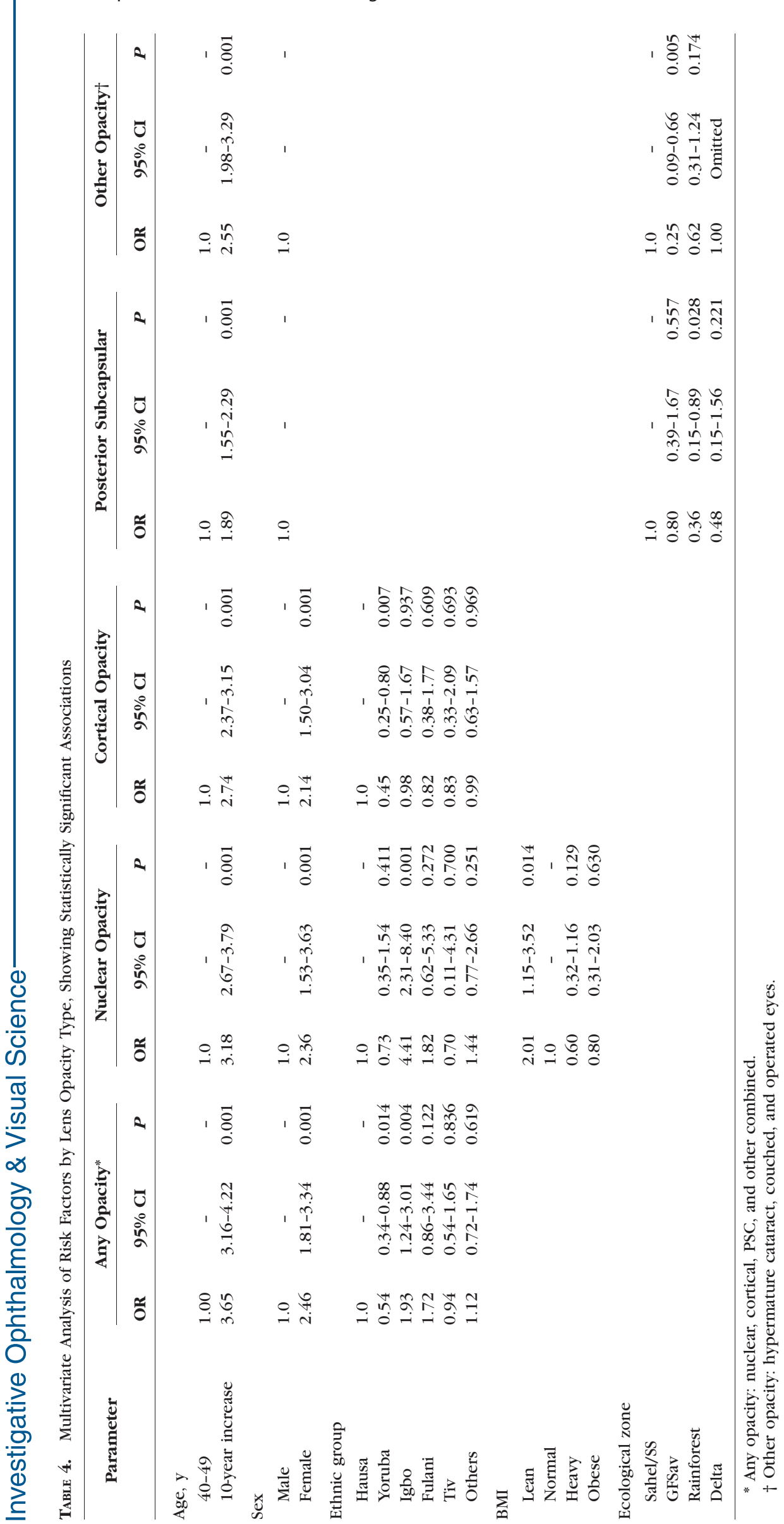


an important determinant, ${ }^{13}$ although evidence from other studies is lacking. If childbearing is an independent risk factor for cataract, then communities without access to reproductive health services ${ }^{32}$ and high fertility rates will be more at risk. In 2003, the fertility rate in Nigeria was 5.7 births/woman (range 4.1 in the southern geopolitical zones to 7.0 in the northeast), which is among the highest in the world. Over $20 \%$ of women aged younger than 20 years have had their first child, and $20 \%$ of married women do not have access to modern contraception. ${ }^{32}$ All these parameters are worse in northern areas. However, childbearing was not explored in this study.

In our study, the Yoruba ethnic group had a significantly lower risk of any lens opacity and $\mathrm{CO}$, while the Igbo ethnic group had significantly greater risk of any lens opacity and NO. Reasons for the ethnic variation may reflect genetic, environmental, cultural or behavioral differences, or may be due to residual confounding. However, there are likely to be other differences between ethnic groups that have an impact on the risk of lens opacities, including diet.

Lean BMI was an independent risk factor for NO, but not other types. The association between BMI and lens opacities is complex, with some studies-mainly undertaken in industrialized or middle income countries-showing an increased risk with greater BMI or central adiposity. ${ }^{12,33-35}$ Other studies have demonstrated a J-shaped association with both lean and high BMI conferring greater risk (e.g., Pakistan). ${ }^{7}$ Lean BMI was associated with greater risk in Myanmar ${ }^{29}$ and among Chinese Singaporeans. ${ }^{36}$ In developing countries, it is likely that the association between lean BMI and lens opacity is confounded by low socioeconomic status and reflects chronic malnutrition with antioxidant deficiency, and exposure to other risk factors associated with poverty such as frequent episodes of severe diarrhea. ${ }^{13}$

In our study, over half of all participants lived in a household where no one was literate. Although lack of literacy was associated with an increased risk of all types of lens opacities in univariate analysis (including any lens opacity), it did not remain significant in multivariable analysis. Level of education is said to be a good proxy indicator of health, ${ }^{37}$ but it may not be as discriminating in communities with very poor levels of education overall. Low education is also likely to be confounded by many other factors, such as poverty, access to services, type of employment, nutritional status, exposure to indoor biomass cooking fuels, ${ }^{10}$ and poor access to clean water and sanitation, which was also not an independent risk factor in our study. One explanation for the latter may be because the majority of households had a very low environment and sanitation index, with $66.5 \%$ of households using a bore well or unprotected water source and a pit latrine or open defecation.

Analysis of data from the Pakistan national survey of blindness showed a significant association between high average annual temperature and lens opacity, with high annual average rainfall being protective. ${ }^{7}$ However, in Nigeria average annual mean temperature is fairly uniform across the country and rainfall much higher in southern areas than northern. Exploration of climatic factors was beyond the scope of this study, as this requires the use of local climate data from weather stations or interpolated data, assessment of colinearity between climate variables, and complex statistical analyses that adjust for environmental as well as individual risk factors. ${ }^{38}$

It has been suggested that lens opacities may be a useful marker of biological aging ${ }^{39}$ and several studies have reported higher mortality rates in those with cataract than those without. ${ }^{40,41}$ Aging entails a complex interplay of molecular, cellular, and system level processes, and exposure to environmental factors such as smoking and a low antioxidant diet accelerate these processes. More research is needed to identify exposures that are likely to accelerate the aging process and 
risk of chronic systemic and ocular disease. Research is needed to explore chronological and biological aging both within and between populations, to better understand mechanisms which may explain the higher prevalence and earlier age at onset of lens opacity in developing countries.

The strength of this study was its large sample size, with clusters selected across the country. All examinations were performed by highly qualified ophthalmologists after an intense period of training. A limitation of the study is that interobserver agreement studies were not undertaken, but the finding that the proportion of participants scored as having no opacities were similar between the two main observers for all types of opacity suggests that were was no systematic measurement error.

In conclusion, further studies are needed to explore risk factors for different types of lens opacity in African countries, to explore ethnicity, childbearing, exposure to biomass cooking fuels, childbearing, and climatic variables, some of which are potentially modifiable or might change over time.

\section{Acknowledgments}

The authors thank the Federal Ministry of Health, state governments, and local governments in Nigeria for providing accommodations to the survey teams and other administrative and logistical support during the survey. We also thank Oye Quaye for managing the finances for the study; Auwal Shehu and Dania Charles for data entry; and the teams of ophthalmic nurses, enumerators, interviewers, liaison officers, drivers, and cooks in the six geopolitical zones who assisted with data collection.

Supported by Sightsavers International, Velux Stiftung, and Christofel Blind Mission. The authors alone are responsible for the content and writing of the paper.

Disclosure: A.M. Mahdi, None; M. Rabiu, None; C. Gilbert, None; S. Sivasubramaniam, None; G.V.S. Murthy, None; C. Ezelum, None; G. Entekume, None

\section{References}

1. Gower E, West S. Age-related cataract. In: Johnson GJ, Minassain DC, Weale RA, West SK, eds. The Epidemiology of Eye Disease. 3rd ed. London: Imperial College Press; 2012.

2. Congdon N, Broman KW, Lai H, Munoz B, et al. Cortical, but not posterior subcapsular, cataract shows significant familial aggregation in an older population after adjustment for possible shared environmental factors. Ophthalmology. 2005;112:73-77.

3. Hammond CJ, Duncan DD, Snieder H, et al. The heritability of age-related cortical cataract: the twin eye study. Invest Ophthalmol Vis Sci. 2001;42:601-605.

4. Kelly SP, Thornton J, Edwards R, Sahu A, Harrison R. Smoking and cataract: review of causal association. $J$ Cataract Refract Surg. 2005;31:2395-2404.

5. Mathew MC, Ervin AM, Tao J, Davis RM. Antioxidant vitamin supplementation for preventing and slowing the progression of age-related cataract. Cochrane Database Syst Rev. 2012;6: CD004567.

6. Murthy GV, Gupta SK, Maraini G, et al. Prevalence of lens opacities in North India: the INDEYE feasibility study. Invest Ophthalmol Vis Sci. 2007;48:88-95.

7. Shah SP, Dineen B, Jadoon Z, et al. Lens opacities in adults in Pakistan: prevalence and risk factors. Ophthalmic Epidemiol. 2007; 14:381-389.

8. West S. Ocular ultraviolet B exposure and lens opacities: a review. J Epidemiol. 1999;9(suppl 6);S97-S101.

9. McCarty CA, Taylor HR. A review of the epidemiologic evidence linking ultraviolet radiation and cataracts. Dev Ophthalmol. 2002;35:21-31.
10. Fullerton DG, Bruce N, Gordon SB. Indoor air pollution from biomass fuel smoke is a major health concern in the developing world. Trans $R$ Soc Trop Med Hyg. 2008;102: 843-851.

11. Pokhrel AK, Bates MN, Shrestha SP, Bailey IL, Dimartino RB, Smith KR. Biomass stoves and lens opacity and cataract in Nepalese women. Optom Vis Sci. 2013;90:257-268.

12. Glynn RJ, Christen WG, Manson JE, Bernheimer J, Hennekens $\mathrm{CH}$. Body mass index. An independent predictor of cataract. Arch Ophthalmol. 1995;113:1131-1137.

13. Minassian DC, Mehra V, Jones BR. Dehydrational crises from severe diarrhoea or heatstroke and risk of cataract. Lancet. 1984; 1:751-753.

14. Minassian DC, Mehra V, Reidy A. Childbearing and risk of cataract in young women: an epidemiological study in central India. Br J Ophthalmol. 2002;86:548-550.

15. Dineen B, Gilbert CE, Rabiu M, et al. The Nigerian national blindness and visual impairment survey: rationale, objectives and detailed methodology. BMC Ophthalmol. 2008;8:17.

16. Thylefors B, Chylack LT Jr, Konyama K, et al. A simplified cataract grading system. Ophthalmic Epidemiol. 2002;9:8395.

17. Taylor HR, West SK. The clinical grading of lens opacities. Aust N Z J Ophthalmol. 1989;17:81-86.

18. Komolafe OO, Ashaye AO, Ajayi BG, Bekibele CO. Visual impairment from age-related cataract among an indigenous African population. Eye (Lond). 2010;24:53-58.

19. Congdon N, West SK, Buhrmann RR, Kouzis A, Muñoz B, Mkocha $\mathrm{H}$. Prevalence of the different types of age-related cataract in an African population. Invest Ophthalmol Vis Sci. 2001; $42: 2478-2482$.

20. Leske MC, Connell AM, Wu SY, Hyman L, Schachat A. Prevalence of lens opacities in the Barbados Eye Study. Arch Ophthalmol. 1997;115:105-111.

21. West SK, Muñoz B, Schein OD, Duncan DD, Rubin GS. Racial differences in lens opacities: the Salisbury Eye Evaluation (SEE) project. Am J Epidemiol. 1998;148:1033-1039.

22. Athanasiov PA, Edussuriya $\mathrm{K}$, Senaratne $\mathrm{T}$, et al. Cataract in central Sri Lanka: prevalence and risk factors from the Kandy Eye Study. Ophthalmic Epidemiol. 2010;17:34-40.

23. Nirmalan PK, Krishnadas R, Ramakrishnan R, et al. Lens opacities in a rural population of southern India: the Aravind Comprehensive Eye Study. Invest Ophthalmol Vis Sci. 2003; 44:4639-4643.

24. Srinivasan M, Rahmathullah R, Blair CR, et al. Cataract progression in India. BrJ Ophthalmol. 1997;81:896-900.

25. Landers J, Henderson T, Prevalence Craig J. Prevalence and associations of cataract in indigenous Australians within central Australia: the Central Australian Ocular Health Study. Clin Experiment Ophthalmol. 2010;38:387-392.

26. Cheng CY, Liu JH, Chen SJ, Lee FL. Population-based study on prevalence and risk factors of age-related cataracts in Peitou, Taiwan. Zhonghua Yi Xue Za Zhi (Taipei). 2000;63:641-648.

27. Hirvelä H, Luukinen $H$, Laatikainen L. Prevalence and risk factors of lens opacities in the elderly in Finland. A populationbased study. Ophthalmology. 1995;102:108-117.

28. Xu L, Cui T, Zhang S, et al. Prevalence and risk factors of lens opacities in urban and rural Chinese in Beijing. Ophthalmology. 2006;113:747-755.

29. Athanasiov PA, Casson RJ, Sullivan T, et al. Cataract in rural Myanmar: prevalence and risk factors from the Meiktila Eye Study. Br J Ophthalmol. 2008;92:1169-1174.

30. West SK, Valmadrid CT. Epidemiology of risk factors for agerelated cataract. Surv Ophthalmol. 1995;39:323-334.

31. Abraham AG, Condon NG, West Gower EW. The new epidemiology of cataract. Ophthalmol Clin North Am. 2006; 19:415-425. 
32. Sedgh G, Bankole A, Okonofua F, Imarhiagbe C, Hussain R, Wulf D. Meeting young women's sexual and reproductive health needs in Nigeria. New York: Guttmacher Institute; 2009. Available at: http://www.guttmacher.org/pubs/2009/ 06/03/ASRH_Nigeria.pdf. Accessed December 30, 2013.

33. Hiller R, Podgor MJ, Sperduto RD, et al. A longitudinal study of body mass index and lens opacities. The Framingham Studies. Ophthalmology. 1998;105:1244-1250.

34. Jacques PF, Moeller SM, Hankinson SE, et al. Weight status, abdominal adiposity, diabetes, and early age-related lens opacities. Am J Clin Nutr. 2003;78:400-405.

35. Leske MC, Wu SY, Hennis A, Connell AM, Hyman L, Schachat A. Diabetes, hypertension, and central obesity as cataract risk factors in a black population. The Barbados Eye Study. Ophthalmology. 1999; 106:35-41.

36. Foster PJ, Wong TY, Machin D, Johnson GJ, Seah SK. Risk factors for nuclear, cortical and posterior subcapsular cataracts in the Chinese population of Singapore: the Tanjong Pagar Survey. Br J Ophthalmol. 2003;87:1112-1120.

37. Winkleby MA, Jatulis DE, Frank E, Fortmann SP. Socioeconomic status and health: how education, income, and occupation contribute to risk factors for cardiovascular disease. $\mathrm{Am} \mathrm{J}$ Public Health. 1992;82:816-820.

38. Clements AC, Kur LW, Gatpan G, et al. Targeting trachoma control through risk mapping: the example of Southern Sudan. PLoS Negl Trop Dis. 2010;4:e799.
39. Pathai S, Shiels PG, Lawn SD, Cook C, Gilbert C. The eye as a model of ageing in translational research-molecular, epigenetic and clinical aspects. Ageing Res Rev. 2013;12:490-508.

40. Cugati S, Cumming RG, Smith W, Burlutsky G, Mitchell P, Wang JJ. Visual impairment, age-related macular degeneration, cataract, and long-term mortality: the Blue Mountains Eye Study. Arch Ophthalmol. 2007;125:917-924.

41. Xu L, Cui TT, Wang YX, Jonas JB. Cataract and mortality. The Beijing eye study. Graefes Arch Clin Exp Ophthalmol. 2008; 246:615-617.

42. Seah SK, Wong TY, Foster PJ, Ng TP, Johnson GJ. Prevalence of lens opacity in Chinese residents of Singapore: the Tanjong Pagar survey. Ophthalmology. 2002;109:2058-2064.

\section{APPENDix}

\section{Nigeria National Blindness and Visual Impairment Study Group}

Adenike Abiose, Olufunmilayo Bankole, Abdullahi Usman Imam, Elizabeth Elhassan, Fatima Kyari, Hannah Faal, Pak Sang Lee, and Tafida Abubakar, in addition to the other authors of the article. 